\title{
Por favor, chamem a professora! Relato de uma Experiência Clínica
}

Nadja Nara Barbosa Pinheiro'

Maria Vitória Mamede Maia"

'Universidade Federal do Paraná (UFPR), Curitiba/PR - Brasil "Universidade Federal do Rio de Janeiro (UFRJ), Rio de Janeiro/RJ - Brasil

RESUMO - Por favor, chamem a professora! Relato de uma Experiência Clínica. O artigo propõe uma reflexão sobre a possibilidade do encontro com os conceitos teóricos psicanalíticos, na universidade, seja capaz de provocar certo mal-estar, em alguns alunos, diante do qual um pedido de ajuda pode ser endereçado aos professores de psicanálise. Em resposta, cientes de que, como professores, não respondemos do lugar do analista, acreditamos, entretanto, que devemos nos posicionar desde o lugar da psicanálise. Objetivando sustentar tal posicionamento, um episódio em que uma aluna da graduação se tranca em uma das salas da universidade chamando por sua professora será tomado como o exemplo paradigmático de uma experiência que se configurou como clínica para além dos domínios de um processo analítico.

Palavras-chave: Experiência Clínica. Psicanálise. Universidade. Freud. Winnicott.

ABSTRACT - Please, Call the teacher! A Clinical Experience Report. The
article reflects on the possibility that the encounter with psychoanalytic
theoretical concepts in the university may cause, in some students, a dis-
comfort from what they ask for help to their psychoanalysis teachers. Be-
ing aware that, as teachers, we do not answer to them as their analyst, we
believe, however, that we must stand up from the point of view of psycho-
analysis. Aiming to support such position, an episode in which an under-
graduate student locks herself in one of the rooms of the university calling
for her teacher will be taken as a paradigmatic example of an experience
that became clinical, beyond the domains of an analytical process.
Keywords: Clinic Experience. Psychoanalysis. University. Freud. Winnicott.

Educação \& Realidade, Porto Alegre, v. 40, n. 3, p. 883-898, jul./set. 2015. 883 http://dx.doi.org/10.1590/2175-623644720 
Por favor, chamem a professora!

\section{Por favor, chamem a professora! Relato de uma Experiência Clínica}

Há alguns anos somos professoras universitárias responsáveis por disciplinas cujas ementas versam sobre a teoria da psicanálise. Durante esses anos, uma particularidade tem chamado nossa atenção. Não raramente, observamos que o encontro com os conteúdos psicanalíticos ao longo dos semestres acadêmicos, é capaz de produzir, como efeito, a emergência de um mal-estar difuso em nossos alunos. Em alguns casos, tal acontecimento se torna o ponto de partida para a busca por um tratamento psicanalítico e, frequentemente, nós somos solicitadas a indicarmos um analista. Situação que nos parece significar, em seu bojo, a existência de uma transferência conosco - e com a psicanálise - sendo construída pelo alunato.

Para outros alunos, no entanto, o desconforto suscitado se apresenta de uma forma mais intensa e a demanda por ajuda não é emitida por meio de uma verbalização, mas se apresenta pela via da atuação, e os alunos, não raro, direcionam seu pedido de ajuda diretamente para nós, seus professores.

É sobre essa segunda modalidade de situação que o presente artigo discorre. Nele partimos de um episódio ocorrido nas dependências de uma universidade no qual uma aluna se tranca em uma das salas exigindo a presença de sua professora de psicanálise (uma das autoras deste artigo) nitidamente angustiada e desorganizada. Desse acontecimento, Freud e Winnicott serão os autores que nos sustentarão no sentido de afirmarmos dois posicionamentos distintos, porém, complementares, pois acreditamos que, diante da solicitação de ajuda efetuada pelos alunos, uma resposta deva ser oferecida no sentido de acolher e dar contornos a um sofrimento cujo pedido de ajuda nos foi endereçado.

Primeiramente, gostaríamos de indicar que o fato de sermos professoras, por um lado, nos impede de respondermos ao pedido de ajuda de nossos alunos a partir do lugar de analistas. Porém, por outro lado, acreditamos que, uma vez que estamos inseridas no campo da psicanálise, faça parte de nossa responsabilidade, responder à essa solicitação desde um lugar da psicanálise, qual seja, a partir da convicção sobre a existência do Inconsciente que implica na assunção de uma subjetividade clivada em constante movimento e conflito. Em segundo lugar, acreditamos que a possibilidade de assumir esse lugar de resposta se baseia sobre a nossa própria transferência com a psicanálise. Pois somente ela é capaz de sustentar nossa convicção de que uma experiência pode se tornar clínica ainda que sua ocorrência se estabeleça fora de um processo analítico propriamente dito.

Visando fundamentar a primeira proposição, nos apoiaremos em Freud e seu alerta sobre a possibilidade de que o uso dos conceitos teóricos da psicanálise fora da relação clínica pode se tornar selvagem,

884 Educação \& Realidade, Porto Alegre, v. 40, n. 3, p. 883-898, jul./set. 2015. 
na medida em que a teoria só deve ser utilizada como via de acesso aos conteúdos do Inconsciente dos pacientes. Movimento este que deve ocorrer apenas no seio do laço transferencial que este estabelece entre pacientes e analistas.

Em sequência, a sustentação de nossa segunda proposição se dará por meio da apresentação do evento que deu início às reflexões aqui presentes. Para melhor compreendê-lo, a teoria de Winnicott sobre o desenvolvimento emocional nos fornecerá as bases para entendermos o retraimento e o silêncio como mecanismos de defesa erigidos contra a ameaça de desorganização referente ao Ego e, talvez, simultaneamente, de invasão ao verdadeiro-self. Nesse sentido, responder ao apelo da aluna a partir de um lugar da psicanálise significou a decisão em receber o endereçamento de sua atuação, transformando-a em um gesto comunicacional. Se isso não nos desvelou nada a respeito de seus desejos ou de suas fantasias inconscientes, resguardou-os de forma a permitir que a aluna alcançasse uma recuperação parcial de seu equilíbrio emocional de forma suficiente para sustentar a esperança em um trabalho psicanalítico futuro. Motivo pelo qual estamos entendendo esse acontecimento como uma genuína experiência clínica, ainda que tenha se desenrolado em um ambiente acadêmico. Mais precisamente, uma experiência cujo desenrolar não se estabeleceu ao longo de um tratamento psicanalítico, mas que, no entanto, foi capaz de produzir um efeito subjetivo que permitiu à professora oferecer à aluna uma sustentação da angústia que brotava de forma a devolver a essa última, a organização emocional necessária à abertura de um processo clínico propriamente dito em um momento posterior.

\section{Entre a Selvageria e um Lugar de Acolhimento}

Sabemos que desde sua fundação, as relações entre psicanálise e universidade são conturbadas e difíceis de serem sustentadas. A partir de nossa própria experiência, observamos que uma das maiores dificuldades encontradas no ensino da psicanálise na universidade se refere ao fato de que, nesta última, o encontro dos alunos com a psicanálise se estabelece pela via acadêmica e não pela via da clínica, como pacientes. Tal fato é o responsável por produzir uma dificuldade especifica na transmissão da psicanálise, na medida em que, como sabemos, a convicção nos mecanismos do inconsciente são derivativos da transferência que ocorre na clínica e não derivativas de um estudo teórico. No entanto, embora cientes de que a clínica seja um dos pilares estruturantes da inserção no campo da psicanálise, a universidade não oferece instrumentos que obriguem o alunato a se submeterem a um processo analítico. Até mesmo porque não há como se iniciar um processo clínico pela via da obrigatoriedade, na medida em que o sofrimento se apresenta, com exclusividade, como a porta de entrada para a busca de um tratamento psicanalítico.

Educação \& Realidade, Porto Alegre, v. 40, n. 3, p. 883-898, jul./set. 2015. 
Por favor, chamem a professora!

No entanto, o que a experiência como professoras de psicanálise tem nos demonstrado é que embora, nas universidades, o encontro com os conteúdos teóricos da psicanálise seja processado fora do espaço clínico dificultando a transmissão da psicanálise, ele é capaz de produzir efeitos diversos, que levam a resultados distintos. Ou seja, às vezes, o encontro com a psicanálise provoca uma resistência aos seus conteúdos, às vezes maior interesse sobre os mesmos, às vezes um mal- estar que endereça os alunos à busca de atendimento clínico. Importa salientar que em qualquer um desses casos, há um efeito subjetivo produzido nesse encontro a partir do que o aluno precisa se posicionar e os professores manejarem. Um manejo sempre difícil na medida em que o ensino da psicanálise requer a transmissão de algo relativo ao Inconsciente que não se reduz ao plano da aprendizagem intelectual. No entanto, se esses são entraves reais encontrados por todos que ensinam psicanálise nas universidades, acreditamos que os mesmos devam ser tomados como desafios e não como obstáculos derradeiros na medida em que acreditamos na importância do ensino da psicanálise nas universidades.

Historicamente, podemos observar, que o próprio Freud se deparou com esses mesmos questionamentos para sustentar seu desejo em seguir a carreira docente na Universidade de Viena. Segundo Peter Gay (1986) talvez essas dificuldades não tenham se referido, exclusivamente, ao crescente antissemitismo que vigorava na Europa à época, mas igualmente, e talvez principalmente, ao valor revolucionário das teses que a teoria psicanalítica apresentava. Segundo o autor, a teoria freudiana trazia à baila inúmeros afetos e desejos que contradiziam a restrita moralidade da modernidade vienense, repressora e vitoriana, produzindo, em decorrência uma grande resistência e repúdio na sociedade. Acreditamos que tal afirmação indique, por uma via distinta da nossa, que o encontro com o aparato conceitual da psicanálise é capaz de provocar respostas intensas naqueles que tomam contato com seus conteúdos.

Não obstante, o que mais nos importa aqui é destacar o fato que, embora o próprio Freud (1976a) tenha afirmado que a universidade não se apresente como o lugar privilegiado para a transmissão da psicanálise, ela se apresenta como um ótimo lugar para sua divulgação. Em sua opinião, a formação dos analistas deve ser resguardada às instituições psicanalíticas, pois nelas encontramos o lugar ideal para a oferta do tripé sobre o qual a formação em psicanálise se processa - estudo teórico, clínica sob supervisão e, principalmente análise pessoal. No entanto, ainda que não seja o local próprio à formação de analistas, a universidade muito tem a ganhar ao ofertá-la em seus currículos. Pois, na psicanálise, os alunos encontram um rico material de compreensão sobre a subjetividade e de tratamento clínico. Em suas palavras:

Para o objetivo que temos em vista (nas universidades) será suficiente que ele (o aluno) aprenda algo sobre psicanálise

886 Educação \& Realidade, Porto Alegre, v. 40, n. 3, p. 883-898, jul./set. 2015. 
e que aprenda algo a partir da psicanálise. Afinal de contas a formação universitária não equipa o estudante de medicina para ser um hábil cirurgião; e ninguém que escolha a cirurgia como profissão pode evitar uma formação adicional, sob a forma de vários anos de trabalho no departamento cirúrgico de um hospital (Freud, 1976a, p. 217).

Concordando com a posição freudiana, acreditamos, igualmente, que é importante mantermos o ensino da psicanálise nas universidades a despeito das dificuldades que aí encontramos. Entre elas, destacamos aqui que a apresentação dos conteúdos teóricos da psicanálise é capaz de colocar em movimento algo do inconsciente de nossos alunos. E, para melhor circunscrevermos a nossa questão, primeiramente parece-nos importante promovermos uma distinção entre dois níveis do saber. Aquele que se apresenta como exposto, racional e conceitual, e outro nível do saber, referente ao Inconsciente, sobre o qual nada se sabe, à priori, mas pelo qual um analista se orienta durante um processo analítico. Sobre o saber racional, cognitivo, compreensível, as disciplinas da universidade se organizam e sua apresentação é feita de modo a permitir um ensino coeso que facilite sua aprendizagem. Acreditamos que tal dimensão também esteja incluída, e seja aproveitada, apropriadamente, nas disciplinas que versam sobre a psicanálise. No entanto, acreditamos, igualmente, que o ensino da psicanálise deva levar em conta a dimensão de um saber que conduz ao desejo inconsciente. É essa dimensão (imprescindível, diga-se de passagem) que comporta um imbroglio que algumas vezes temos que lidar, nas universidades, não do lugar do analista, mas, como psicanalistas, durante o exercício de outra função: a de docentes. Ou seja, se o encontro com a psicanálise, ainda que pela via teórica, é capaz de produzir mal-estar, e, em consequência a emergência de um pedido de ajuda, o difícil nessa demanda é que nossa resposta, certamente, não poderá vir do lugar do analista, uma vez que não ocupamos essa função junto aos nossos alunos. No entanto, acreditamos que a questão não seja tão simples assim e não se esgote nessa condição. Em nossa perspectiva, por sermos professoras que se dedicam a transmitir um saber que versa sobre o inconsciente $\mathrm{e}$ seus desdobramentos, temos, sobre a emergência da angústia de nossos alunos, uma responsabilidade da qual não podemos nos furtar. E se não podemos dar conta dessa responsabilidade a partir do lugar do analista, com certeza, dela devemos dar conta desde um lugar da psicanálise.

Mas, como isso pode ser feito? Pois sabemos, desde Freud, que aquilo que sustenta e justifica as intervenções de um psicanalista é a relação estabelecida entre ele e seu paciente, no interior da clínica, via estabelecimento da transferência. Fora da relação clínica, nos alerta o autor as intervenções, por mais que sejam corretas em suas relações com o desejo inconsciente, se tornam violentas, invasivas e selvagens. Em um de seus textos, Freud (1976b) discorre claramente sobre esse assunto. Nele, o autor se refere a um episódio no qual ele próprio é procurado por 
Por favor, chamem a professora!

uma senhora com a intenção de dirimir uma dúvida. Ela havia procurado um médico (que se intitulava psicanalista) porque vinha sofrendo de estados ansiosos desde que se divorciara de seu marido. Ansiedade esta que se intensificara após a consulta médica, pois o médico, diante do relato da paciente, diagnosticara que a senhora estava padecendo de uma neurose de angústia derivada de sua abstinência sexual prolongada e auto infringida. Indica, então, três alternativas para a senhora se curar: ela deveria ou casar-se de novo, ou encontrar um amante, ou masturbar-se. Diante dessas alternativas, a senhora se sente indignada, pois não entende qual poderia ser a relação entre a angústia e a sexualidade e procura Freud questionando-o, não apenas sobre o diagnóstico médico, mas sobre o próprio saber da psicanálise. Freud, então, ao longo de seu texto vai demonstrando que o que estava em jogo ali, para além de uma questão teórica sobre a verdade ou não dos conceitos psicanalíticos, relacionava-se a uma questão clínica. O que o médico não havia levado em conta era o fato de que toda e qualquer interpretação sobre os movimentos psíquicos de um paciente deve estar inscrita no campo clínico, ou seja, sustentada pela transferência, pois fora dele, qualquer interpretação, por mais acertada que possa ser, se torna invasiva. Em suas palavras:

\begin{abstract}
De vez, no entanto, que a psicanálise não pode abster-se de dar essa informação (sobre as razões inconscientes do sintoma), prescreve que isto não se poderá fazer antes que duas condições tenham sido satisfeitas. Primeiro, o paciente deve, através de preparação, ter alcançado ele próprio a proximidade daquilo que ele reprimiu e, segundo, ele deve ter formado uma ligação suficiente (transferência) com o médico para que seu relacionamento emocional com este torne uma nova fuga impossível (Freud, 1976b, p. 208).
\end{abstract}

Ou seja, esse texto se mostra como um excelente alerta para que não façamos uso de nossos conhecimentos teóricos quando não estamos autorizados para tal. Uma autorização que nos é concedida quando alguém nos procura e solicita uma ajuda em relação a um sofrimento que o própria pessoa não está conseguindo resolver. O importante é perceber que essa solicitação se configura apenas como o início de um processo que necessita de tempo e de trabalho minucioso para se estabelecer e dar frutos. Posto que, o analista depende, sobretudo, que a transferência ganhe espaço suficiente tanto para indicar os movimentos do Inconsciente como para dar sustentação às intervenções relativas ao trabalho do analista. Novamente, nas palavras de Freud:

A intervenção, portanto, requer de maneira absoluta um
período bastante longo de contato com o paciente. As ten-
tativas de surpreendê-lo na primeira consulta, inopina-
damente lhe contando os segredos que foram descobertos
pelo médico, são tecnicamente inadmissíveis. E elas, as 888 Educação \& Realidade, Porto Alegre, v. 40, n. 3, p. 883-898, jul./set. 2015. 
mais das vezes, trazem sua própria punição por produzirem uma franca inimizade pelo médico da parte do paciente, e por impedi-lo de ter qualquer influência ulterior (Freud, 1976b, p. 209).

Mas, avancemos mais um pouco no texto freudiano. Nele, o autor faz uma pequena observação que nos parece bastante valiosa e preciosa para nossos propósitos. Ele nos informa que, embora o médico tenha interpretado de forma selvagem a angústia de sua paciente, ele fez mais pela jovem senhora do que aqueles que diagnosticariam uma causa orgânica para os sofrimentos psíquicos, posto que sua intervenção abriu as portas para a dúvida e o interesse da jovem senhora sobre os enigmas de seu desejo.

No caso da senhora cuja queixa contra seu médico ouvimos, eu devia dizer que, apesar de tudo, o psicanalista 'silvestre' fez mais por ela do que alguma autoridade altamente respeitada que lhe tivesse dito que ela estava sofrendo de uma 'neurose vasomotora'. Ele forçou a atenção dela para a verdadeira causa de seu distúrbio, ou nessa direção, e não obstante toda a oposição dela, essa sua intervenção não pode ter ficado sem resultados favoráveis (Freud, 1976b, p. 212).

Interessante posicionamento esse de Freud, não? Pois ainda que o médico tenha produzido alguns enganos, tanto teórico quanto clínico, ele produziu um interessante efeito analítico, pois ele permitiu que as portas à psicanálise permanecessem abertas. Ele permitiu que um interesse clínico fosse mantido fazendo com que, em sequência, a paciente procurasse Freud no intuito que este pudesse auxiliá-la a entender seu sofrimento. Assim, se a atuação desse médico suscitou uma intensa resistência ao tratamento, por outro lado fez emergir, igualmente, uma transferência ao saber psicanalítico. Em suma, o que nos interessa destacar nesse exemplo oferecido por Freud é o fato de que mesmo fora da condução de um tratamento analítico algo da transferência com a psicanálise pôde se apresentar. É essa a ideia que sustenta nossa decisão em levarmos em consideração o pedido de ajuda de nossos alunos, sem, no entanto, assumirmos o lugar do analista, mas o de alguém que, ao reconhecer em sua própria pele, a potência da pulsão e do Inconsciente, se apresenta, como suporte, para acolher a angústia daquele que sofre.

\section{Por favor: chamem a professora! ${ }^{1}$}

Fui, durante quatro anos consecutivos, professora de uma universidade na qual era responsável pelo ensino de algumas disciplinas de psicanálise. Naquela oportunidade, pude acompanhar uma mesma turma ao longo desses anos, o que, claro, facilitou a ocorrência de um vínculo bastante estável com alguns de meus alunos. Entre estes, Daniela. 
Por favor, chamem a professora!

Daniela fazia parte de um pequeno grupo de alunos que se interessavam bastante pela psicanálise e que participavam, de forma intensa, das aulas. No entanto nada, no grupo, me parecia anunciar o que estava prestes a ocorrer. Em uma manhã, cheguei à universidade e, como de costume me encaminhei para a sala dos professores. Quando lá cheguei, uma das secretárias me disse: Professora, que bom que a senhora chegou! Uma de nossas alunas se trancou em um das salas de atendimento do CPA (Centro de Psicologia Aplicada) e disse que só abrirá a porta para a senhora. Nos dirigimos, a secretária e eu, para o CPA. Lá, encontramos outras alunas. Todas tão preocupadas quanto eu. Senti que, quando me viram, ficaram aliviadas, como se eu soubesse o que estaria ocorrendo e poderia ajudar. Ledo engano, eu estava tão surpresa quanto elas e não fazia a menor ideia do que levara Daniela a tomar essa atitude. Bati à porta. Daniela respondeu, perguntando: Já chamaram a professora? Respondi: Sim, sou eu, Daniela. Estou aqui, pode abrir a porta. Ela abriu a porta, nada falou, sentou-se ao sofá e me pediu pra trancar a porta, novamente, quando eu entrei. Assim o fiz. Sentei na cadeira puxando-a para perto do sofá em que Daniela permanecia recostada. Perguntei: O que houve? Daniela me olhou e disse: Precisava que você estivesse aqui comigo. Respondi: Estou aqui. Daniela me olhou longamente e disse: Não tenho o que falar, só preciso que você fique aqui comigo, um pouco. Respondi: Está bem, e me calei. Daniela recostou-se no sofá e se calou. Às vezes cerrava os olhos e assim permanecia por longos períodos. Porém eu percebia que não adormecia, apenas ficava de olhos fechados com um semblante sossegado como quem está meditando. Às vezes abria os olhos e me olhava como quem queria se certificar de que eu ainda estava ali. Nesses momentos, eu sentia algo diferente: um olhar intenso, inseguro, de procura, de busca por algo. Nesses momentos, eu sentia o fio da angústia brotando. Ao encontrar meu olhar, Daniela, novamente sossegava, cerrava os seus.

Ficamos assim, por um tempo, que me pareceu muito longo. Ao final, Daniela se levantou e me disse: Obrigada, professora. Já podemos ir. Perguntei: Para onde? Ela sorriu e me disse: Eu vou pra casa, professora. A senhora ainda tem que dar aulas, não? Respondi afirmativamente. E nos encaminhamos para a porta, mas eu estava apreensiva. Eu estava meio inquieta com o fato de ela ir pra casa sozinha. Olhei para ela e perguntei: Daniela, para que eu fique mais tranquila, eu gostaria de pedir que uma de suas amigas te acompanhasse até em casa. Você concorda? Daniela respondeu que sim com a cabeça. A quem eu devo chamar? Perguntei. Helena, respondeu. Pedi à Helena que acompanhasse Daniela até em casa. As duas se foram. Algum tempo depois, Helena me ligou contando que as duas chegaram bem na casa da Daniela, que nada comentou sobre o assunto e pouco falou no trajeto. Contou-me que Daniela havia procurado, na véspera, um psicanalista e que iria iniciar um tratamento. Fiquei mais sossegada. Essas foram as únicas informações que tive. Daniela continuou a frequentar as aulas, fazer as provas, con-

890 Educação \& Realidade, Porto Alegre, v. 40, n. 3, p. 883-898, jul./set. 2015. 
cluir os semestres e a ter um contato comigo como antes, como se nada houvesse ocorrido. Nunca tocamos no assunto.

Durante muito tempo fiquei pensando no que houve ali. Sei que algo ocorreu. Algo forte, algo que produziu uma sensação de sossego, que a acalmou e a assegurou de alguma coisa fundamental. O que seria?

\section{Uma Experiência Clínica para além de um Processo Analítico}

Todos nós que nos dedicamos ao ensino sabemos que os alunos desenvolvem conosco relações afetivas a partir das quais eles nos endereçam inúmeras demandas. Na maioria das vezes essas solicitações se resumem a pedidos de ajuda quanto a questões acadêmicas ou pedagógicas. Entretanto, há casos em que eles nos pedem algum tipo de conselho e orientação não apenas referente ao campo universitário, mas também pessoal. Nesses momentos, partimos do princípio que todas as respostas que oferecemos aos nossos alunos estarão marcadas pelo crivo da transferência, uma vez que esta não é uma exclusividade da análise (Freud, 1976c), e produzirão efeitos não apenas intelectuais, mas igualmente subjetivos. No entanto, tais experiências compartilhadas com nossos alunos não podem ser definidas como clínicas, como estamos tentando caracterizar a experiência vivenciada por Daniela e sua professora. Ou seja, alguns elementos concorreram no sentido de fazer com que esse episódio em particular se mostrasse, para nós, como um exemplo singular de experiência clínica ainda que um tratamento analítico não estivesse em andamento.

Claro que o fato de Daniela ter utilizado as dependências da universidade dedicadas ao atendimento clínico de pacientes externos pelos alunos no cumprimento de seus estágios obrigatórios não nos passou despercebido. Pareceu-nos que esse movimento indicava uma flagrante tentativa de arrastar a relação acadêmica para uma relação terapêutica.

Igualmente, parece-nos importante demarcar que a atitude de Daniela aponta para um pedido específico de ajuda. Uma ajuda que endereçada a uma pessoa em particular, sua professora de psicanálise, indica que podemos inserir esse pedido no seio da transferência e das relações objetais. Ou seja, há aí o indicativo sobre a existência de uma organização egoica que pressupõe a distinção entre o Eu e o não-Eu no decurso do processo de constituição da subjetividade que, em contrapartida, permite que um objeto (a professora) fosse situado na exterioridade.

Esses três elementos - a tentativa de inserir a relação acadêmica em uma perspectiva terapêutica, a suposição sobre a existência de uma organização egoica capaz de distinguir um Eu de um não-eu e a capacidade de situar alguém (a professora) como um objeto externo e com ela produzir relações de objeto - serão tomados como ponto de partida 
Por favor, chamem a professora!

para nossas argumentações e tentativa de entendimento sobre o tipo de experiência ali vivenciada.

\section{Construção do Eu e dos Objetos: um processo}

Para entendermos esse processo estamos aqui tomando como fundamento a teoria formulada por Winnicott (1990) sobre o desenvolvimento emocional e afetivo segundo a qual, para que seja possível a um indivíduo alcançar o estágio de desenvolvimento no qual as relações com objetos externos são uma realidade, faz-se necessário que um longo caminho tenha sido percorrido anteriormente. Um caminho que se inicia por meio da criação de objetos subjetivos, regulados sob a égide do controle onipotente pelo bebê, que ao ser paulatinamente matizado, permite o deslocamento gradativo do lugar no qual os objetos são situados, de subjetivos para objetivamente percebidos. Em termos subjetivos, isso equivale a dizer que por meio do deslocamento do lugar ocupado pelos objetos a criança consegue promover uma distinção entre seu mundo interno e a realidade externa, local no qual consegue situar alguns objetos e a perceber que tais objetos já não se submetem ao seu controle onipotente. Passagem promovida por meio de objetos que se posicionam na condição de transicionais na medida em que fundam uma ponte, uma intermediação entre a interioridade e a exterioridade.

Segundo Winnicott (1975), paralelamente a esse processo de criação e constituição de objetos, não apenas as áreas distintas de localização desses objetos estão sendo criadas, como, igualmente, os modos específicos de com eles lidar. Assim, à área referida ao mundo interno, os objetos subjetivos nela habitam e são regulados pela fantasia e o controle onipotente. Já os objetos objetivamente percebidos, pertencem à realidade externa e escapam ao controle onipotente e fantasio uma vez que possuem autonomia em relação ao mundo interno, psíquico. Os objetos transicionais, por sua vez, fornecem o solo para a construção de uma terceira área, uma área fronteiriça, tanto interna quanto externa, na qual a operacionalidade de compartilhamento entre o interno e o externo se torna possível. Nessa terceira área, de sobreposição, a experiência de trocas, de compartilhamento, de transformações que inserem enriquecimento nas realidades interna e externa se tornam reais. Nas palavras do autor:

Experimentamos a vida na área dos fenômenos transicionais, no excitante entrelaçamento da subjetividade e da observação objetiva, e numa área intermediária entre a realidade interna do indivíduo e a realidade compartilhada do mundo externo aos indivíduos (Winnicott, 1975, p. 93).

Importa salientar que, na proposta winnicottiana, o processo de constituição da subjetividade é pautado por movimentos provenientes da interioridade e da alteridade, pois nele concorrem tanto a força vital do bebê quanto os modos de acolhimento ofertado pelo ambiente a 
esta. Em sua perspectiva, portanto, o ambiente se reveste de importância ao sustentar e prover as condições necessárias ao viver, tanto biológico quanto psíquico, ao fornecer sustentação, sentidos, significações, amparo e contenção à não-integração primordial de um bebê.

\begin{abstract}
No contexto do relacionamento do bebê com o seio materno (e não estou declarando que o seio é essencial como veículo de amor da mãe) o bebê tem impulsos instintivos e ideias predatórias. A mãe tem o seio e o poder de produzir leite, e a ideia de que ela gostaria de ser atacada por um bebê faminto. Esses dois fenômenos não estabelecem uma relação entre si até que a mãe e o bebê vivam juntos uma experiência (Winnicott, 2000, p. 227).
\end{abstract}

Ou seja, na perspectiva do autor, ao nascer, há um potencial ao desenvolvimento em todo ser humano que necessita encontrar um ambiente suficientemente bom de forma a permitir que o desenvolvimento emocional aconteça. Uma vez o ambiente tenha fornecido as condições necessárias, a tendência natural à integração se realiza e as vivências inicialmente não integradas se organizam em torno de um núcleo - o ego. Nesse sentido, portanto, a conquista de uma unidade egoica é paralela à criação dos objetos e dos modos de relações que vão sendo estabelecidos, pois a percepção de um mundo externo, paradoxalmente, depende e funda a percepção de um mundo interno, de uma delimitação entre o Eu e o Não-Eu.

Por outro lado, o fato da organização egoica tratar-se de uma conquista inclui a possibilidade de desorganização. Ameaça diante da qual, inúmeros mecanismos de defesa são erigidos na tentativa de manter a organização operante. Vejamos como podemos o modo como esse processo se estabeleceu na situação aqui analisada.

\title{
O Silêncio como Defesa e Proteção do Verdadeiro-Self
}

Em nosso entender, essa perspectiva de Winnicott se apresenta como favorecedora do entendimento do que ocorreu entre Daniela e sua professora. O fato de Daniela poder discriminar um objeto de eleição para ajudá-la nesse momento considerado por ela como ameaçador, nos indica que houve, nos primórdios de sua vida subjetiva, um ambiente satisfatório que permitiu que a integração egoica fosse, minimamente, alcançada. E o que nos parecia, por meio de sua atitude, era que, por algum motivo desconhecido, essa organização egoica conquistada se apresentava sob risco e Daniela gritou por socorro. Uma ameaça que não era pequena, pois Daniela não apenas se fechou em uma sala mas como também teve necessidade de chaveá-la. Mesmo com a presença de sua professora lá dentro com ela.

Por nossa experiência clínica, sabemos que a intensidade da defesa geralmente é diretamente proporcional à intensidade da ameaça. Uma defesa tão intensa erigida por alguém cuja organização egoica já 
Por favor, chamem a professora!

fora alcançada e que apresentava condições de promover relações com objetos externos, nos pareceu indicativo de um movimento que visava proteger algo ainda mais primitivo que o próprio Ego: o verdadeiro-self. Verdadeiro-self que, na perspectiva winnicottiana, recobre um elemento relativo ao potencial criativo, sendo, portanto, o que há de mais genuíno em cada ser humano e que, por isso mesmo, deve ser arduamente protegido de qualquer ameaça de intromissão efetuada pelo ambiente.

No intuito de melhor entender tal movimento, partimos da proposição de Winnicott (1983a) que situa a divisão do ego entre um verdadeiro e um falso self na necessidade de que uma parte do ego se dirija e estabeleça relações com a realidade externa. O fato de parte do Ego estar em contato com a realidade externa o mantém aberto às invasões e intromissões perpetradas pelo ambiente, assim, ao se dividir, o ego pode manter uma parte de si longe do contato com a realidade e as ameaças que este impõe. A parte reclusa do ego, então, se mantém preservada, preservando algo da realidade psíquica, inconsciente, do contato com o exterior. Em nosso entendimento, portanto, verdadeiro self pode ser concebido como a parte mais íntima de cada ser humano que por seu caráter inconsciente mantém-se desconhecida até mesmo do próprio sujeito que o porta. No entanto, exatamente por isso, constitui-se como o que há de mais genuíno e verdadeiro a partir do que a movimentação subjetiva se mantém viva ao longo da existência de cada ser humano. $\mathrm{O}$ alcance à exterioridade se estabelece via desdobramentos do verdadeiro-self, isto é, partes do ego que, por obrigações sociais, se comunicam com a alteridade, com a realidade compartilhada, denominadas pelo autor por falso-self. Neste sentido, Winnicott afirma:

Há um aspecto submisso do self verdadeiro no viver normal, uma habilidade do lactente de se submeter e de não se expor. A habilidade de conciliação é uma conquista. $\mathrm{O}$ equivalente ao self verdadeiro no desenvolvimento normal é aquele que se pode desenvolver na criança no sentido das boas maneiras sociais, algo que é adaptável. Na normalidade essas boas maneiras sociais representam uma conciliação (Winnicott, 1983a, p. 137).

O falso-self, portanto, é fundamental na medida em que desempenha funções transicionais entre interioridade e exterioridade mantendo o isolamento do verdadeiro-self preservado e assegurado. É essa função transicional que permite que as relações estabelecidas com a realidade externa mantenham-se conectadas com o verdadeiro-self e possam ser sentidas como vivências qualitativamente reais, sentidas afetivamente como verdadeiras. Caso essa possibilidade transicional se perca, as relações com o mundo se tornam apagadas, sem sentido e vivenciadas como falsas, como não reais.

Não à toa, Winnicott (1983b) nos chama a atenção para o fato que a intenção deliberada em cortar a comunicação com o mundo pode significar uma defesa extrema contra a sensação de invasão ao verda-

894 Educação \& Realidade, Porto Alegre, v. 40, n. 3, p. 883-898, jul./set. 2015. 
deiro-self. Nesse sentido, o autor aponta para a possibilidade que, em alguns casos, o silêncio pode representar uma tentativa de defesa e de recuperação do equilíbrio emocional em ameaça de ser perdido. O importante é percebermos que, como defesa, a intenção de não manter comunicação, já porta em si mesmo, uma possibilidade de comunicar-se. Tal como a decisão de Daniela em se trancar em uma sala e nada dizer sobre o seu mal-estar e angústia, constitui como uma forma de dizer ao mundo o quanto ela estava sofrendo.

No entanto, para que o processo comunicacional se estabeleça, ainda que pela via do silêncio, é necessário que o seu endereçamento seja reconhecido por outro ser humano, que ao acolher a encenação do mal-estar a reconhece como, portanto, uma mensagem impedindo, com isso, que uma ação deliberada caia no abismo do não-sentido.

Para melhor compreendermos esse processo, retornemos às considerações de Winnicott (1983a) sobre as origens do verdadeiro-self. Estas, segundo o autor, remontam aos estágios mais primitivos do desenvolvimento emocional, caracterizado pela total dependência do bebê dos cuidados a ele conferidos pela Mãe-ambiente. Nesse momento, o bebê premido por suas necessidades vitais, se movimenta, esperneia e chora sem que seus movimentos indiquem uma intencionalidade qualquer. No entanto, esses movimentos alcançam a mãe que, identificada a seu bebê, ilusoriamente é capaz de decodificar os movimentos não intencionais de seu filho satisfazendo suas necessidades vitais básicas. Essa capacidade materna de antever, em uma pura movimentação desordenada, uma comunicação em potencial é a responsável por transformar uma ação não intencional em gesto, em comunicação. Nesse sentido, podemos entender que a mãe-ambiente, ao dar colo, ao amparar, ao sustentar seu bebê, ela é capaz de organizar e legitimar sua existência.

Não nos parece, portanto, que tenha sido à toa que Daniela precisou da presença de sua professora para singularizar e tornar significativo seu gesto de defesa e proteção de seu verdadeiro-self. Pois somente frente a outro ser-humano, a ação, a movimentação, pode se tornar um gesto e ser significada, ainda que esse nível estejamos tomando contato com um tipo de comunicação silenciosa. Porém é algo que antecipa e torna possível a comunicação pela via da linguagem e da simbolização.

\section{Experiência Clínica: algumas proposições}

O difícil nas situações clínicas, e mais ainda na situação vivenciada com Daniela, é que diferentemente de uma mãe que se prepara, tanto fisiológica quanto psicologicamente, durante a gestação de forma a poder exercer satisfatoriamente suas funções, na clínica, nos momentos em que ocorre a irrupção de um movimento que se expressa pela via do ato e não da simbolização, o analista não tem esse tempo de adaptação. Geralmente os pacientes exigem uma resposta imediata a suas 
Por favor, chamem a professora!

angústias e, nem sempre os analistas se encontram preparados para suportar o sem-sentido de seus pacientes por algum tempo visando incluí-lo no campo da comunicação significativa. Tal impossibilidade de suportar o insuportável, às vezes, é responsável pela escolha do analista em arriscar uma interpretação que, na verdade, serve, apenas, para aplacar sua própria angústia. Como vimos acima, Freud já nos indicava que nesses momentos de precipitação a teoria psicanalítica é utilizada como recurso e se torna selvagem. Ou como indica Winnicott, estes são os momentos em que a interpretação se torna uma invasão, que como uma flecha, é capaz e varar as defesas erigidas, justificadamente, pelo paciente. Nas palavras do autor: "Estupro, ser devorado por canibais, isso são bagatelas comparados com a violação do núcleo do self pela comunicação varando as defesas" (Winnicott, 1983b, p. 170).

Talvez o fato de Daniela não ser uma paciente e sua professora não ser sua analista, tenha contribuído para que esta última não tenha se utilizado do recurso interpretativo para acalmar sua própria angústia na medida em que não havia elementos clínicos que justificassem uma interpretação e a professora teve que aguardar, também, em silêncio, o momento em que para Daniela foi possível retornar à vida cotidiana. Com esse seu posicionamento, a professora pôde ser incluída no campo das relações objetais de Daniela e promover, a partir daí, uma função transicional capaz de fazê-la recuperar seu equilíbrio emocional, sustentando, para Daniela a angústia que aflorava. Com seu gesto, a professora pôde se tornar um objeto que ocupou distintas posições e exerceu distintas funções. Ela se tornou um objeto subjetivo, sob o controle onipotente de Daniela, na medida em que respondeu ao pedido de socorro e veio ao seu encontro na hora em que foi necessária. Permaneceu nessa condição por um tempo X também necessário para que Daniela recuperasse seu equilíbrio. Paralelamente e simultaneamente apontando para a existência de uma exterioridade, situando-se no espaço concreto da realidade compartilhada, o que era constantemente verificado por Daniela nos momentos em que abria os olhos e encontrava a professora ao seu lado. Momentos em que esta última se apresentava como suporte para receber, acolher e acalmar a angústia de Daniela, funcionando, então, como um objeto transicional, que pode ser usado (no sentido que Winnicott confere ao termo) como ponte à exterioridade. $\mathrm{O}$ alcance à exterioridade culmina com o descarte da professora como objeto transicional e o retorno de Daniela à sua vida cotidiana com seu equilíbrio parcialmente recuperado. Não apenas pelo fato de ter conseguido sair da sala, mas igualmente, por ter retomado suas atividades diárias como atestou sua frequência à vida acadêmica.

Toda essa movimentação nos parece configurar uma atividade completamente clínica, embora, é claro, resguardada as limitações de efeitos subjetivos impostos pelo fato de não haver um processo analítico em atividade. O que, no entanto, não o desqualifica em valor e intensidade.

896 Educação \& Realidade, Porto Alegre, v. 40, n. 3, p. 883-898, jul./set. 2015. 


\section{Finalizando}

As considerações que apresentamos acima tiveram seu início marcado por meio de um episódio singular, de rara ocorrência no âmbito universitário. Pelo menos com essa intensidade. No entanto, acreditamos que vários são os momentos em que, ao desempenharmos nossas funções como docentes, somos solicitados por nossos alunos a responder suas demandas e seus pedidos de ajuda. Nossa intenção com esse breve relato foi a de reafirmarmos a nossa opinião que o fato de sermos professores nos impede de respondermos do lugar do analista, no entanto, o fato de sermos psicanalistas nos exige que arquemos com a responsabilidade inerente ao exercício de nossa função. E igualmente, nos vemos obrigadas a responder desde um lugar da psicanálise: qual seja, daquele que reconhece a existência do inconsciente e da intensidade da angústia que nos constitui como seres-humanos. Difícil tarefa de ser cumprida posto que, embora ocorra a existência de uma relação transferencial entre alunos e professores, tal relação não nos dá o direito de agirmos como se fôramos seus analistas, posto não haver um tratamento em andamento. Nesse sentido, acreditamos que aquilo que nos permitirá discernir qual a justa medida de nossa atitude será a nossa própria transferência à psicanálise. Em última instância é essa transferência que nos permitirá, em algumas circunstâncias e situações, discernir, o momento em que é fundamentalmente necessário suportarmos algo que é da ordem do insuportável para um outro ser humano e permitir com essa atitude que algo da clínica aí opere. Felizmente, em nossas análises pessoais, encontramos em nossos analistas, alguém igualmente disposto a fazer o mesmo por nós.

Recebido em 20 de janeiro de 2014 Aprovado em 28 de novembro de 2014

\section{Nota}

1 Como a situação relatada remete à uma das autoras, o texto, a partir deste momento, passará a ser narrado na primeira pessoa do singular.

\section{Referências}

FREUD, Sigmund. Deve a Psicanálise ser Ensinada na Universidade. In: FREUD, Sigmund. Edição Standard Brasileira das Obras Psicológicas Completas de Sigmund Freud. Tradução J. Salomão. Rio de Janeiro: Imago. Volume XVII. 1976a. P. 217-219.

FREUD, Sigmund. Psicanálise Silvestre. In: FREUD, Sigmund. Edição Standard Brasileira das Obras Psicológicas Completas de Sigmund Freud. Tradução J. Salomão. Rio de Janeiro: Imago, 1976b. Volume XI. P. 205.

FREUD, Sigmund. Observações sobre o Amor Transferencial. In: FREUD, Sigmund. Edição Standard Brasileira das Obras Psicológicas Completas de Sigmund Freud. Tradução J. Salomão. Rio de Janeiro: Imago, 1976c. Volume XII. P. 207-221. 
GAY, Peter. Freud: uma vida para nosso tempo. Rio de Janeiro: Companhia das Letras, 1986.

WINNICOTT, Donald. Objetos e Fenômenos Transicionais. In: WINNICOTT, Donald. O Brincar e a Realidade. Tradução J. A. Abreu e V. Nobre. Rio de Janeiro: Imago, 1975. P. 13-44.

WINNICOTT, Donald. Distorção do Ego em Termos de Falso e Verdadeiro 'self'. In: WINNICOTT, Donald. O Ambiente e os Processos de Maturação: estudos sobre a teoria do desenvolvimento emocional. Tradução D. I. C. S. Ortiz. Porto Alegre: Artes Médicas, 1983a. P. 130-153.

WINNICOTT, Donald. Comunicação e Falta de Comunicação Levando ao Estudo de Certos Opostos. In: WINNICOTT, Donald. O Ambiente e os Processos de Maturação: estudos sobre a teoria do desenvolvimento emocional. Tradução D. I. C. S. Ortiz. Porto Alegre: Artes Médicas, 1983b. P. 163-174.

WINNICOTT, Donald. Natureza Humana. Rio de Janeiro: Imago, 1990.

WINNICOTT, Donald. Desenvolvimento Emocional Primitivo. In: WINNICOTT, Donald. Da Pediatria à Psicanálise: Obras Escolhidas. Tradução J. Russo. Rio de Janeiro: Imago, 2000. P. 218-232.

Nadja Nara Barbosa Pinheiro é psicóloga (UFRJ), especialista em Psicoterapia (IPUB/UFRJ), mestre (UFRJ) e doutora (PUC/RJ) em Psicologia; Professora da Graduação e do Programa de Pós-graduação em Psicologia do Departamento de Psicologia da Universidade Federal do Paraná; Coordenadora do Laboratório de Psicanálise (DEPSI/UFPR), no qual desenvolve, dentre outros, o projeto de pesquisa: "Corpo e Psicanálise: reflexões sobre os fenômenos psicossomáticos a partir do trabalho clínico".

E-mail: nadjanbp@hotmail.com

Maria Vitória Mamede Maia é doutora em Psicologia (PUC-Rio), mestre em Letras (PUC-Rio), Psicopedagogia (UNICEUB) - BsB, Psicanalista (CPRJ), Professora Doutora da Faculdade de Educação da Universidade Federal do Rio de Janeiro, Professora do Programa de Pós-Graduação em Educação da UFRJ, Coordenadora do grupo de pesquisa Criar e Brincar: o lúdico no processo de ensino-aprendizagem e do Espaço de Atendimento Psicopedagógico da Faculdade de Educação da UFRJ.

E-mail: mariavitoriamaia@gmail.com 